\title{
The Treatment of Morton's Neuroma, a Significant Cause of Metatarsalgia for People Who Exercise
}

\author{
Balalis Konstantine $^{1}$, Topalidou Anastasia ${ }^{1}$, Balali Catherine ${ }^{2}$, Tzagarakis George ${ }^{1}$, Katonis Pavlos $^{1}$ \\ ${ }^{1}$ University of Crete-Faculty of Medicine, Department of Orthopaedics and Traumatology, University Hospital of Heraklion, \\ Heraklion, Greece; ${ }^{2}$ University of the Aegean, Mitilini, Greece. \\ Email:kbalalis1@gmail.com, atopalidou@gmail.com
}

Received November $15^{\text {th }}, 2012$; revised December $29^{\text {th }}, 2012$; accepted January $17^{\text {th }}, 2013$

\begin{abstract}
Morton's Neuroma is a common metatarsalgia in athletes created due to the entrapment of the inter-digital nerve inside the transverse inter-metatarsal ligament. The purpose of the present study is to draw the necessary conclusions from the use of a particular surgical treatment to release the digital nerve, accompanied by neurolysis in adults who exercise. On the whole, twenty five patients with twenty-five suffering extremities were treated. Five of them simultaneously had a Hallux Valgus type deformity and that supports the belief of the mechanical induce of this condition. Both ultrasonography and Magnetic Resonance Imaging (MRI) were used for the clinical evaluation of this condition. The pain was estimated via the Visual Analogue Scale (VAS). The patients were re-examined after three (1st postoperative), twelve (2nd postoperative) and twenty-four ( 3 rd postoperative) months. A significant improvement $(p<0.0001)$ was noticed from the correlation between the pain before the surgery and the pain after the surgery via the Visual Analogue Scale (VAS). Most patients (15/25) did not display any discomfort or sensory disorder after surgery. The correct clinical evaluation as well as the correct and effective surgical intervention with the simultaneous repair of all the mechanical deformities of the foot provided better post-surgery progress in patients and increased the percentage of their rehabilitation of their previous activities.
\end{abstract}

Keywords: Morton's Neuroma; Neurolysis; Metatarsalgia; Surgical Technique

\section{Introduction}

Morton's neuroma is mostly a mechanically-induced degenerative neuropathy which is most frequently found in the third inter-digital nerve [1,2]. The main causes of Morton's neuroma remain vague. It is probably a form of compressive peripheral neuropathy which is related to the excessive use of inappropriate footwear and it is most frequently seen in people, such as runners and ballet dancers, who participate in sports activities that include high strain on the foot $[3,4]$. Usually, the symptoms are not immediately noticeable by the athletes who are used to feeling such discomfort during preparation, training or a competition. As a result they go to a specialist only in serious and persisting cases $[4,5]$.

\subsection{Parthogenesis}

It is mostly caused by repeated minor injuries in the plantar digital nerve, which is entrapped between the transverse intermetatarsal ligament and the fascia [1,6]. The distal positions of the spinal extension of the metatarsal joints, like the case of abnormal pronation, intensify the nerve's entrapment by bringing it in a more disadvantaged position. Secondly, the neuroma could grow due to the increased pressure, as well. Also, pathological-anatomical findings, such as perineural and endoneural fibrosis, fibrillar degeneration and demyelination, often reveal the existence of compressive neuropathy [7]. Morton's neuroma is usually seen in runners when the third metatarsal joint is extended more than the fourth metatarsal joint [4].

\subsection{Treatment}

First of all, the treatment is conservative and it includes abstinence from exercise, change of footwear type, orthoses, injection of Non-Steroidal Anti-Inflammatory Drugs (NSAIDs) and local injection of corticosteroids. In case of persisting or recurrent symptoms, surgical treatment is suggested and it aims at the nerve's release (neurolysis) and the excision of the neuroma in intense cases $[3,6,8]$.

The purpose of the present study is to draw the necessary conclusions from the use of this specific surgical treatment for the release of the digital nerve, accompanied by neurolysis in adults who exercise. 


\section{Patients and Methods}

During the period 2000-2010 twenty five patients with twenty-five extremities suffering from Morton's neuroma were treated in the General University Hospital of Heraklion and the Diagnostic-Therapeutic-Surgical Center "Asklepieon Crete". Fifteen of them were women and 10 were men. The average age of group was 32.80 years (19 - 43 years). Their anthropometric characteristics are shown in Table 1. All patients were amateurs who exercised systematically and six of them played tennis, four were hikers, five played football and the other ten jogged. The mean value of their symptoms' appearance was at 7 months (5 - 11 months). Five patients had a Hallux Valgus type deformity simultaneously. In order to estimate the pain, the patients were asked to indicate the length of the pain via the Visual Analogue Scale (VAS) (Table 2) [9]. Also, the sensory disorders were classified (Table 3) and the activities which caused the pain were recorded (Table 4). The diagnosis of the syndrome was based on the patient's medical history, the clinical examination, the examination by lidocaine infusion and the illustrative check via ultrasonography and MRI (Table 5). The patients were re-examined after three (1st postoperative), twelve (2nd postoperative) and twenty-four (3rd postoperative) months.

\subsection{Operative Technique}

The surgery was done with local anaesthesia and tourniquet. The access to the suffering space was dorsal and elongate between the metatarsi, identifying the anterior extremity of the plantar fascia. The two metatarsi were repelled with hooks in order to acutely release the deep under-strain fascia and the inter-metatarsal ligament, which was simultaneously protected with the digital vessels, away from the neighboring neuroma. The surgery was done with the help of magnification and perineural neurolysis in 18 cases. In the end, there was a convergence of the trauma and the patient was allowed to walk 24 hours after the surgery, as long as the release of the digital nerve was the only surgery he underwent.

\subsection{Statistical Analysis}

All analyses were carried out with the SPSS ${ }^{\circledR}$ statistical

Table 1. Anthropometric characteristics of 25 patients with Morton's Neuroma enrolled in the study.

\begin{tabular}{ccc}
\hline Characteristic & Sample size & Patients \\
\hline Age (years) & 25 & $32.80 \pm 6.81$ \\
Height $(\mathrm{cm})$ & 25 & $171.24 \pm 8.31$ \\
Weight $(\mathrm{kg})$ & 25 & $66.22 \pm 8.77$ \\
Body mass index $\left(\mathrm{kg} / \mathrm{m}^{2}\right)$ & 25 & $24.51 \pm 2.37$ \\
\hline
\end{tabular}

*Data presented as mean $\pm \mathrm{SD}$.
Table 2. Intensity of the pain pre- and post-operatively (VAS score).

\begin{tabular}{|c|c|c|c|c|}
\hline \multicolumn{5}{|c|}{ VAS score (pain) } \\
\hline Foot's No & Preoperative & $\begin{array}{l}\text { Postoperative } \\
\text { (3 months) }\end{array}$ & $\begin{array}{l}\text { Postoperative } \\
\text { (12 months) }\end{array}$ & $\begin{array}{l}\text { Preoperative } \\
\text { (24 months) }\end{array}$ \\
\hline 1 & 8 & 0 & 0 & 0 \\
\hline 2 & 9 & 2 & 2 & 2 \\
\hline 3 & 8 & 1 & 1 & 1 \\
\hline 4 & 8 & 2 & 2 & 2 \\
\hline 5 & 8 & 1 & 1 & 1 \\
\hline 6 & 9 & 2 & 2 & 8 \\
\hline 7 & 10 & 7 & 7 & 7 \\
\hline 8 & 6 & 2 & 2 & 2 \\
\hline 9 & 7 & 2 & 2 & 2 \\
\hline 10 & 7 & 1 & 1 & 1 \\
\hline 11 & 6 & 0 & 0 & 0 \\
\hline 12 & 7 & 1 & 1 & 1 \\
\hline 13 & 9 & 7 & 7 & 7 \\
\hline 14 & 9 & 2 & 2 & 2 \\
\hline 15 & 8 & 2 & 2 & 2 \\
\hline 16 & 8 & 1 & 1 & 1 \\
\hline 17 & 6 & 1 & 1 & 1 \\
\hline 18 & 6 & 2 & 2 & 2 \\
\hline 19 & 10 & 1 & 1 & 1 \\
\hline 20 & 8 & 1 & 1 & 7 \\
\hline 21 & 10 & 6 & 6 & 6 \\
\hline 22 & 8 & 0 & 0 & 0 \\
\hline 23 & 7 & 1 & 1 & 1 \\
\hline 24 & 7 & 1 & 1 & 1 \\
\hline 25 & 7 & 2 & 2 & 2 \\
\hline Mean $( \pm \mathrm{SD})$ & $7.84 \pm 1.248$ & $1.92 \pm 1.913$ & $1.92 \pm 1.913$ & $2.40 \pm 2.449$ \\
\hline
\end{tabular}

package, version 15.0 (SPSS Inc., Chicago, IL, USA) for Windows ${ }^{\circledR}$. The paired t-test was used to compare preand postoperative VAS and the Hedrick and McBryde scores [10]. The null hypothesis was that there would be no difference between the pre- and postoperative values. Rejection of the null hypothesis indicated lower pain and sensory disorders after surgery. The relationship between the patient's pain relief (Hedrick and McBryde score) and pain scale (VAS and VAS sensory disorder score) were tested through Pearson's correlation coefficient. All tests were two-sided and statistical significance was set at $\mathrm{p}<0.05$.

\section{Results}

Overall, 14 3rd inter-digital spaces and 11 2nd interdigital spaces were operated on. Two patients underwent 
Table 3. Intensity of the pain pre- and post-operatively (VAS score).

\begin{tabular}{|c|c|c|c|c|}
\hline \multicolumn{5}{|c|}{ VAS score (seonsory disorders) } \\
\hline Foot's No & Preoperative & $\begin{array}{l}\text { Postoperative } \\
\text { (3 months) }\end{array}$ & $\begin{array}{l}\text { Postoperative } \\
\text { (12 months) }\end{array}$ & $\begin{array}{l}\text { Preoperative } \\
\text { (24 months) }\end{array}$ \\
\hline 1 & 8 & 0 & 0 & 0 \\
\hline 2 & 9 & 2 & 2 & 2 \\
\hline 3 & 8 & 2 & 2 & 2 \\
\hline 4 & 8 & 2 & 2 & 2 \\
\hline 5 & 9 & 2 & 2 & 2 \\
\hline 6 & 7 & 1 & 1 & 4 \\
\hline 7 & 7 & 6 & 6 & 6 \\
\hline 8 & 6 & 2 & 2 & 2 \\
\hline 9 & 5 & 1 & 1 & 1 \\
\hline 10 & 5 & 0 & 0 & 0 \\
\hline 11 & 5 & 0 & 0 & 0 \\
\hline 12 & 6 & 0 & 0 & 0 \\
\hline 13 & 9 & 6 & 6 & 6 \\
\hline 14 & 8 & 1 & 1 & 1 \\
\hline 15 & 7 & 1 & 1 & 1 \\
\hline 16 & 7 & 0 & 0 & 0 \\
\hline 17 & 5 & 0 & 0 & 0 \\
\hline 18 & 4 & 1 & 1 & 1 \\
\hline 19 & 7 & 0 & 0 & 0 \\
\hline 20 & 6 & 0 & 0 & 5 \\
\hline 21 & 8 & 4 & 4 & 4 \\
\hline 22 & 7 & 0 & 0 & 0 \\
\hline 23 & 6 & 0 & 0 & 0 \\
\hline 24 & 5 & 1 & 1 & 1 \\
\hline 25 & 6 & 1 & 1 & 1 \\
\hline Mean $( \pm \mathrm{SD})$ & $6.72 \pm 1.429$ & $1.32 \pm 1.725$ & $1.32 \pm 1.725$ & $1.64 \pm 1.912$ \\
\hline
\end{tabular}

Table 4. Recording the intensity of activities that cause pain.

\begin{tabular}{cc}
\hline Activities & $\begin{array}{c}\text { Number of suffering } \\
\text { extremities }(\mathbf{n}=\mathbf{2 5})\end{array}$ \\
\hline Pain during the up-standing position & 12 \\
Pain during walking & 24 \\
Pain regarding pace & 25 \\
Pain caused by footwear & 25 \\
Pain during the night & 9 \\
Pain during rest & 11 \\
Pain during pressure & 25 \\
\hline
\end{tabular}

simultaneously rectification surgery for the Hallux Valgus in a modified McBride procedure. The post-surgery progress of all patients was normal with no complications or unsightly scars. 14 out of 25 extremities that were
Table 5. The reaction of the suffering extremities to the diagnostic examination.

\begin{tabular}{|c|c|}
\hline Clinical Examination & $\begin{array}{c}\text { Number of suffering } \\
\text { extremities }(n=25)\end{array}$ \\
\hline Positive reaction & 23 \\
\hline Negative reaction & 2 \\
\hline $\begin{array}{c}\text { Examination after lidocaine } \\
\text { infusion }\end{array}$ & $\begin{array}{l}\text { Number of suffering } \\
\text { extremities }(n=25)\end{array}$ \\
\hline Complete reaction & 20 \\
\hline Partial reaction & 5 \\
\hline $\begin{array}{l}\text { Examination with } \\
\text { ultrasonogram (U/S) }\end{array}$ & $\begin{array}{l}\text { Number of suffering } \\
\text { extremities }(n=25)\end{array}$ \\
\hline Positive & 21 \\
\hline Negative & 4 \\
\hline $\begin{array}{l}\text { Examination with Magnetic } \\
\text { Resonance Imaging (MRI) }\end{array}$ & $\begin{array}{l}\text { Number of suffering } \\
\text { extremities }(n=8)\end{array}$ \\
\hline Positive & 7 \\
\hline Negative & 1 \\
\hline
\end{tabular}

Table 6. Evaluation of the post-surgery progress ( 3 months) of the patients on the Hedrick and McBryde scale, modified by Johnson.

\begin{tabular}{|c|c|c|}
\hline $\begin{array}{l}\text { Suffering } \\
\text { extremities }\end{array}$ & Grade & Result \\
\hline $15 / 25(60 \%)$ & Excellent & $\begin{array}{l}\text { Great relief from pain and return to all } \\
\text { sports activities. }\end{array}$ \\
\hline $8 / 25(32 \%)$ & Good & $\begin{array}{l}\text { Great relief from pain during normal } \\
\text { activities, occasional discomfort during } \\
\text { sports activities. }\end{array}$ \\
\hline $2 / 25(8 \%)$ & Moderate & Pain during sports activities \\
\hline $0 / 25(0 \%)$ & $\mathrm{Bad}$ & No relief \\
\hline
\end{tabular}

operated on had a full recovery in three months on average and the patients returned to their previous sports activities. After three months, the patients were re-examined and the results of their progress were estimated on the Hedrick and McBryde scale, modified by Johnson, and they are shown in Table 6. Moreover, the intensity of the pain was re-examined using the Visual Analogue Scale (VAS) and the sensory disorders. Three extremities that were operated on did not display any pain at all, nineteen of them displayed VAS $<5$ and three displayed VAS 5 - 7. Apart from two extremity that displayed moderate sensory disorders, all other extremities were all in all normal. It is worth mentioning that the extremity that displayed vestigial sensory disorders simultaneously had the Hallux Valgus which was not operated on. Pre- and post-operative VAS scores are represented graphically in Figures 1 and 2 . The individual data and mean $\pm \mathrm{SD}$ values of VAS scores are shown in Tables 2 and 3. Mean \pm SD of pain according VAS score was reduced from $7.84 \pm 1.248$ pre-operatively to $1.92 \pm 1.913$ post-operatively $(\mathrm{p}<0.0001,95 \% \mathrm{CI}$ for the mean difference 
between pre- and post-surgery 5.247, 6.593). Between 1 st (at 3 months) and 2nd (at 12 months) post-operative measurement, any statistical significant change of VAS score was observed. Between 2nd (at 12 months) and 3rd (at 24 months) post-operative measurement, any statistical significant change of VAS score was observed $(p=$ $0.161,95 \%$ CI for the mean difference between postoperative $-1.166,0.206$, correspondingly at twelve and twenty-four months). Sensory disorders were reduced from $6.72 \pm 1.429$ pre-operatively to $1.32 \pm 1.725$ postoperatively ( $\mathrm{p}<0.0001,95 \% \mathrm{CI}$ for the mean difference between pre- and post-surgery 4.726, 6.074). Between 1st (at 3 months) and 2nd (at 12 months) postoperative

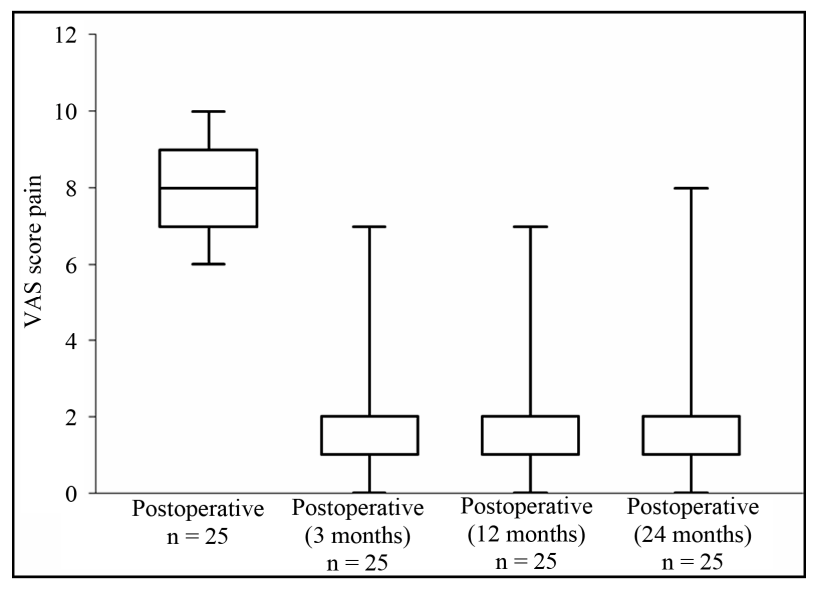

Figure 1. Pre- and post-operative values (3 months), 12 and 24 months of pain along the VAS score. Graphical representation of the distribution (interquartile range); the median value is the horizontal bar inside the interquartile range box. For the values of pain (3, 12 and 24 months) median value of postoperative does exist but it happens to overlap the upper quartile. The slight increase in postoperative VAS score observed in 24 months, due to increase of the pain at that time, for the extremities which had also Hallux Valgus and was not simultaneously repaired.

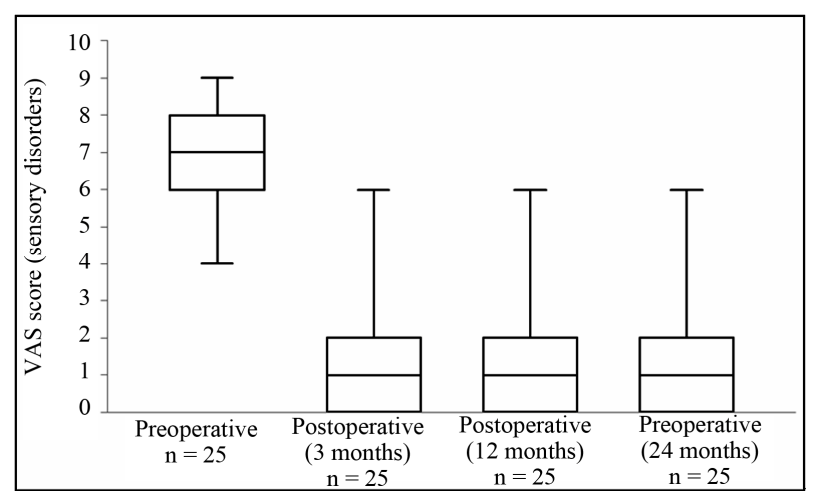

Figure 2. Pre- and post-operative values (3, 12 and 24 months) of sensory disorders along the VAS score. Graphical representation of the distribution (interquartile range); the median value is the horizontal bar inside the interquartile range box. measurement, any statistical significant change of VAS score (sensory disorders) was observed. Between 2nd (at 12 months) and 3rd (at 24 months) post-operative measurement, any statistical significant change of VAS score (sensory disorders) was observed ( $\mathrm{p}=0.175,95 \% \mathrm{CI}$ for the mean difference between post-operative $-0.792,0.152$, correspondingly at three and twenty-four months). The Pearson correlation coefficient between the patient's pain relief (Hedrick and McBryde score) and pain scale (VAS score) for the study group based on pre- and post- (at three months) operative measurements was -0.805 . Figure 3 presents the Hedrick and McBryke scores with respect to the VAS score values. The Pearson correlation coefficient between the patient's pain relief (Hedrick and McBryde score) and pain scale (VAS score-sensory disorders) for the study group based on pre- and post- (at three months) operative measurements was -0.876 . Figure 4 presents the Hedrick and McBryke scores with respect to the VAS score values.



Figure 3. VAS score (pain) versus Hedrick and McBryde score, post-operatively values $\left(R^{2}=0.648\right)$.

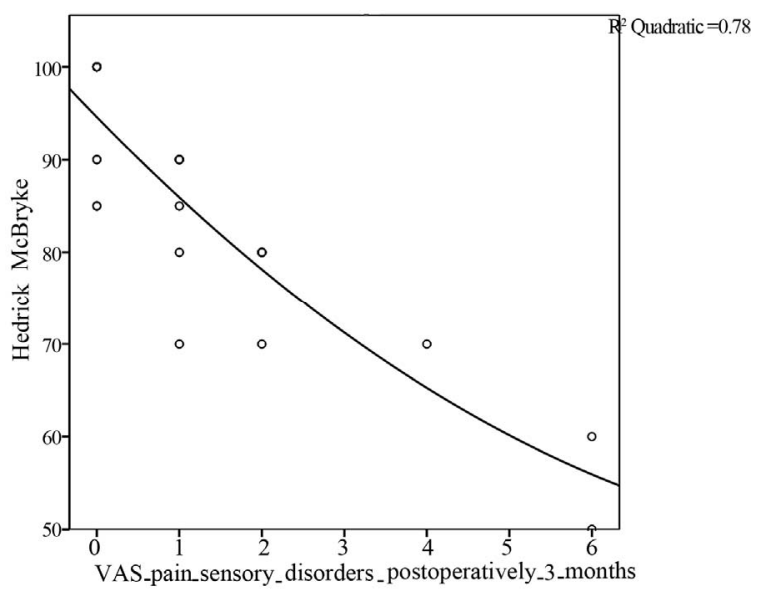

Figure 4. VAS score (sensory disorders) versus Hedrick and McBryde score, post-operatively values $\left(R^{2}=0.780\right)$. 


\section{Discussion}

Morton's Neuroma is a condition of nerve entrapment, particularly painful, which affects a great number of athletes. Firstly the correct diagnosis and secondly the effective treatment play a great role in the proper recovery and rehabilitation of the patient to his previous activities.

Clinical examinations were used for the present studies and their credibility has been proven. Regarding the diagnostic methods, the accuracy of the ultrasonogram is almost the same with the accuracy of a MRI [1,3], It is mentioned that the credibility of each method depends mostly on the size of the mass of the neuroma since the MRI can be accurate even in small tumors, while the ultrasonogram gives a better diagnosis on tumors that are larger than $5 \mathrm{~mm}$ [11]. Also, the MRI helps to eliminate cases where the pressure is caused by some tumor and to demarcate the neuroma $[12,13]$. However, the ultrasonic check remains the easiest and most economical diagnostic method to define the shape and size of Morton's neuroma $[3,13]$.

After the clinical examination, the aim in cases that need surgery must not only be the successful surgical procedure but also the patient's progress after recovery. During the surgery the dorsal access was preferred as it has been proven that it provides a cosmetically better result, fewer complications and it is technically easier. The plantar access is recommended mostly in reviews. Despite the small number of the extremities that were operated on, the positive results of the surgical treatment of neuroma which was depicted in the present study, were great since twenty out of twenty five cases $(80 \%)$ that were treated displayed excellent and stable through time post-surgery results. Similar studies depict good results at $81 \%$ of the cases where an excision of the neuroma was performed [8] and stable results at $83 \%$ of the patients who underwent a release of the nerve [6]. Pace $e t$ al. (2010) [3] note that in cases of excision of the neuroma $82 \%$ of the patients had excellent or good postsurgery results, whereas $10 \%$ of the patients had moderate results with limitations on activities or pain. Also, 8\% of the patients did not show any improvement after surgery. $71 \%$ of these patients had limitations on the use of footwear.

Moreover, as it was mentioned above, Morton's neuroma is mechanically induced, mostly regarding the excessive movement between the third and fourth metatarsal joint. Co-existing conditions of the foot, such as the Hallux Valgus, hammertoe etc, have a negative effect on the mechanically correct movement and function of the foot aggravating the existing physiopathology and the existing neuroma $[1,2,6]$. In the present study a high percentage of co-existing deformities of the anterior portion of the foot (five out of twenty five), such as the Hallux Valgus, were noticed and that affirms the mechanical aetiology of this condition. Also, in the only (three) case where the Hallux Valgus was not simultaneously repaired; the results of the re-examination were not as good compared to the other patients. The symptoms are caused by the existence of both conditions [1] and therefore the simultaneous repair of all the deformities of the anterior portion of the foot is recommended.

In conclusion, it can be said that the correct clinical evaluation, the effective surgical intervention and the simultaneous repair of other deformities of the foot offer a better post-surgery progress for the patients and increase the percentage of their rehabilitation for their previous activities.

\section{REFERENCES}

[1] K. K. Wu, "Morton Neuroma and Metatarsalgia," Current Opinion in Rheumatology, Vol. 12, No. 2, 2000, pp. 131142. doi:10.1097/00002281-200003000-00007

[2] K. K. Wu, "Morton's Interdigital Neuroma: A Clinical Review of Its Etiology, Treatment, and Results," The Journal of Foot and Ankle Surgery, Vol. 35, No. 2, 1996, pp. 112-119. doi:10.1016/S1067-2516(96)80027-5

[3] A. Pace, B. Scammell and S. Dhar, "The Outcome of Morton's Neurectomy in the Treatment of Metatarsalgia," International Orthopaedics, Vol. 34, No. 4, 2010, pp. 511-515. doi:10.1007/s00264-009-0812-3

[4] P. J. Numan and B. D. Giesy, "Management of Morton's Neuroma in Athletes," Clinics in Podiatric Medicine and Surgery, Vol. 14, No. 3, 1997, pp. 489-501.

[5] L. C. Schon and D. E. Baxter, "Neuropathies of the Foot and Ankle in Athletes," Clinics in Sports Medicine, Vol. 9, No. 2, 1990, pp. 489-509.

[6] G. Gauthier, "Thomas Morton's Disease: A Nerve Entrapment Syndrome. A New Surgical Technique," Clinical Orthopaedics and Related Research, Vol. 142, 1979, pp. 90-92.

[7] C. E. Graham and D. M. Graham, "Morton's Neuroma: A Microscopic Evaluation," Foot \& Ankle, Vol. 5, No. 3, 1984, pp. 150-153.

[8] M. M. Ruuskanen, T. Niinimaki and P. Jalovaara, "Results of the Surgical Treatment of Morton's Neuralgia in 58 Operated Intermetatarsal Spaces Followed over 6 (2-12) Years," Archives of Orthopaedic and Trauma Surgery, Vol. 113, No. 2, 1994, pp. 78-80. doi:10.1007/BF00572909

[9] H. Breivik, P. C. Borchgrevink, S. M. Allen, L. A. Rosseland, L. Romundstad, E. K. Breivik Hals, G. Kvarstein and A. Stubhaug, "Assessment of Pain," British Journal of Anaesthesia, Vol. 101, No. 1, 2008, pp. 17-24. doi:10.1093/bja/aen103

[10] M. R. Hedrick and A. M. McBryde, "Posterior Ankle Impingement," Foot \& Ankle International, Vol. 15, No. 1, pp. 2-8.

[11] R. J. Sharp, C. M. Wade, M. S. Henessy and T. S. Saxby, "The Role of MRI and Ultrasound Imaging in Mortons Neuroma and the Effect of Size of Lesion on Symptoms," 
Journal of Bone and Joint Surgery, Vol. 85, No. 7, 2003, pp. 999-1005. doi:10.1302/0301-620X.85B7.12633

[12] D. Weishaupt, K. Treiber, H. P. Kundert, H. Zollinger, P. Vienne, J. Hodler, J. K. Willmann, B. Marincek and M. Zanetti, "Morton Neuroma: MR Imaging in Prone, Supine, and Upright Weight-Bearing Body Positions," Radiology, Vol. 226, No. 3, 2003, pp. 849-856. doi:10.1148/radiol.2263011925

[13] M. J. Lee, S. Kim, Y. M. Huh, H. T. Song, S. A. Lee, J. W. Lee and J. S. Suh, "Morton Neuroma: Evaluated with Ultrasonography and MR imaging," Korean Journal of Radiology, Vol. 8, No. 2, 2007, pp. 148-155. doi:10.3348/kjr.2007.8.2.148 